\title{
Why do models of insect respiratory patterns fail?
}

\author{
John S. Terblanche ${ }^{1, *}$ and H. Arthur Woods ${ }^{2}$
}

\begin{abstract}
Insects exchange respiratory gases using an astonishing diversity of patterns. Of these, discontinuous gas exchange cycles (DGCs) have received the most study, but there are many other patterns exhibited intraspecifically and interspecifically. Moreover, some individual insects transition between patterns based on poorly understood combinations of internal and external factors. Why have biologists failed, so far, to develop a framework capable of explaining this diversity? Here, we propose two answers. The first is that the framework will have to be simultaneously general and highly detailed. It should describe, in a universal way, the physical and chemical processes that any insect uses to exchange gases through the respiratory system (i.e. tracheal tubes and spiracles) while simultaneously containing enough morphological, physiological and neural detail that it captures the specifics of patterns exhibited by any species or individual. The second difficulty is that the framework will have to provide ultimate, evolutionary explanations for why patterns vary within and among insects as well as proximate physiological explanations for how different parts of the respiratory system are modified to produce that diversity. Although biologists have made significant progress on all of these problems individually, there has been little integration among approaches. We propose that renewed efforts be undertaken to integrate across levels and approaches with the goal of developing a new class of general, flexible models capable of explaining a greater fraction of the observed diversity of respiratory patterns.
\end{abstract}

KEY WORDS: Respiration, Metabolic downregulation, Evaporative water loss, Environmental adaptation, Complex systems, Emergent property, Biomimetics

'The fly in the ointment is that, although many insects express a $D G C$, many others, including those that you would predict would express it, such as desert-dwellers, do not. What to make of this? Like me, most scientists are happy to be higher primates preadapted for no good reason to making fabulously complicated twigs with which to fish out delicious and entertaining nuggets from the termite mound of consensual reality.'

Lighton (2007)

\section{Introduction to the range of animal respiratory systems - the fundamentals}

Insect respiratory systems differ by design in fundamental ways compared with all other animal respiratory systems. Essentially, all other known systems consist of a body surface designated for

\footnotetext{
'Department of Conservation Ecology and Entomology, Faculty of AgriSciences, Stellenbosch University, Private Bag X1, Matieland 7602, Stellenbosch, South Africa. 2Division of Biological Sciences, University of Montana, Missoula, MT 59812, USA.

*Author for correspondence (jst@sun.ac.za)

(D) J.S.T., 0000-0001-9665-9405; H.A.W., 0000-0002-3147-516X
}

exchange (the whole surface, lungs, gills, parapodia, everted rectal sacs, etc.). Usually there is convective transport (see Glossary) of oxygen to the exchange surface from the environment, either by external currents of water or by active ventilation of the surface (e.g. 'tidal' ventilation of lungs in mammals). Oxygen then moves inward by diffusion across that surface, and $\mathrm{CO}_{2}$ (usually) moves outward across the same structure. Because most animals are large enough that internal diffusion-based supplies of oxygen become highly inadequate (Schmidt-Nielsen, 1997), they use additional internal systems for distributing the oxygen from the exchange surface to the mitochondria (and removing $\mathrm{CO}_{2}$ ). This they do largely by using muscular pumps that drive internal, oxygencarrying liquids.

The scheme above describes almost all known macroscopic animals. Insects, by contrast, have undergone a quantum shift in several linked aspects of their respiratory biology. Most importantly, they do not appear to rely extensively on circulatory gas transport, although this issue is rather poorly examined. In a few cases where this has been the focus of investigation, the links between heart rate, haemolymph flow, respiratory pigments and respiratory dynamics are not straightforward, perhaps suggesting a role for haemolymph in supporting respiratory gas fluxes in at least some taxa (Hetz et al., 1999; Burmester and Hankeln, 2007). Instead, highly ramified networks of air-filled tracheal tubes deliver oxygen directly, in the gas phase, to within a few micrometres of almost every mitochondrion in the body (Harrison et al., 2012). In a few cases, it has been estimated that $80-90 \%$ of oxygen delivery to tissues occurs via the tracheoles (Snelling et al., 2011, 2012a; see also Schmitz and Perry, 1999), the finest, terminal branches of the tracheal system. $\mathrm{CO}_{2}$ moves back out primarily through the same networks, with the difference that a greater fraction of $\mathrm{CO}_{2}$ may move into the tracheal system directly across tracheal walls (as opposed to entering via tracheoles) (Schmitz and Perry, 1999). The consequences for the respiratory system are 2-fold: first, that no single location in the body is dedicated to gas exchange and, second, that the heart does not play a major role in circulating oxygencarrying blood. In other words, insects possess a two-stage respiration system versus the more complex three-stage respiration systems found in, for example, mammals and most vertebrates and larger organisms.

This evolutionary innovation has a large benefit and a large cost. The benefit derives from how much more rapidly oxygen can be transported in air versus in water or blood. In air, the oxygen capacitance is much higher than in water (although haemoglobin can raise the oxygen capacitance of blood almost to its value in air; e.g. Scheipers et al., 1975), diffusion coefficients of oxygen are about 10,000-fold higher than in water, and because air is so much less dense, it is far easier to pump (Kestler, 1985; Verberk et al., 2016). Thus, the tracheal system has, in many species, evolved into a device that can produce remarkably high mass-specific metabolic rates when needed. High metabolic rates in turn support high mechanical power outputs, and high power, housed in a small body, forms the basis for insect flight (Dudley, 2002), one of the key 


\section{Glossary}

Continuous gas exchange

No pronounced pattern of gas exchange and no clear closed spiracle phase.

\section{Convective transport}

Movement of gases via convection, i.e. aided by some pumping action or muscle work.

C-phase

Closed or constricted spiracle phase of discontinuous gas exchange cycles.

\section{Cyclic gas exchange}

Regular bursts of gas exchange and no prolonged spiracle closure.

DGC

Discontinuous gas exchange cycles.

Fossorial

Underground lifestyle.

F-phase

Fluttering spiracle phase of discontinuous gas exchange cycles; during fluttering, the spiracle opens very briefly, letting oxygen in to the tracheal system and emitting a small pulse of carbon dioxide.

Hypercapnia

Levels of $\mathrm{CO}_{2}$ greater than normal levels.

Lotka-Volterra dynamics

A pair of first-order, non-linear differential equations frequently used to describe the dynamics of biological systems.

$\mu \mathrm{CT}$ scan

Micro-scale or high-resolution computer tomography (threedimensional) scanning

O-phase

Open spiracle phase of discontinuous gas exchange cycles.

$P_{\mathrm{O}_{2}} / P_{\mathrm{CO}_{2}}$

Partial pressure of oxygen or carbon dioxide.

Spiracle

Valve-like opening in an insect's body, capable of regulating flux of respiratory gases.

Xeric

Dry environments.

contributors to their extreme evolutionary diversification (Gaston, 2003; Grimaldi and Engel, 2005).

The offsetting cost is that a system capable of transporting gases at such high rates may perform correspondingly poorly when those high fluxes are not needed - for example, when a flying insect settles down to rest, or when a lineage evolves a non-flying lifestyle. Without additional mechanisms for lowering the overall conductance of the system, the insect would run into a suite of problems, including potentially toxic levels of oxygen in the tissues (Hetz and Bradley, 2005) and high rates of water loss from the respiratory system (Kestler, 1985; Chown, 2002; Woods and Smith, 2010). Most insects appear to have three 'throttling' mechanisms: a distal mechanism, a proximal mechanism and a switch to passive diffusion. The distal mechanism - the spiracle valves (see Glossary) - is operated by muscles that actively close off the tracheal system from the surrounding environment. The design and control of spiracle valves is now well understood (Miller, 1966; Matthews, 2018). The proximal mechanism - liquid filling of the tracheoles (Wigglesworth, 1935; Timmins et al., 2001) - is probably just as important but is much less well understood. The third mechanism for throttling down is to switch from active ventilation (e.g. Wasserthal, 2001; Socha et al., 2010; Greenlee et al., 2009; Lehmann, 2001) to a greater reliance on passive diffusion, which is slower and potentially constrained to some extent by the organism's life stage and morphological structure (e.g. elasticity, or soft or hard cuticle among life stages of lepidopteran larvae, although even an adult beetle or grasshopper with a hard cuticle can have highly dynamic internal respiratory structures; e.g. Socha et al., 2010; Groenewald et al., 2012).

Together, these mechanisms can radically depress the overall conductance of the tracheal system. Doing so, however, creates yet another problem arising from the different capacities of tracheal systems to transport oxygen versus carbon dioxide. Diffusive transport - which is likely to dominate the transport kinetics in tracheal systems that are otherwise throttled back by one of the three mechanisms described above - will magnify the relative importance of differences in molecular size and chemistry among the important gases $\left(\mathrm{O}_{2}, \mathrm{CO}_{2}, \mathrm{H}_{2} \mathrm{O}\right.$ and $\left.\mathrm{N}_{2}\right)$. In particular, $\mathrm{CO}_{2}$ is larger than $\mathrm{O}_{2}$ and has a correspondingly smaller diffusion coefficient in air (Denny, 1993); and water is smaller and has a correspondingly larger diffusion coefficient. Moreover, $\mathrm{CO}_{2}$ is far more soluble in water than is $\mathrm{O}_{2}$, and it can build up to much higher levels in body liquids, with important consequences for acid-base balance (Greenlee and Harrison, 1998; Förster and Hetz, 2010). These effects together mean that, in their low-conductance states, tracheal systems are plagued by too little transport of $\mathrm{CO}_{2}$ compared with transport of $\mathrm{O}_{2}$; they do not let $\mathrm{CO}_{2}$ out fast enough, and it builds up in the body to the point where emergency measures have to be taken (opening the spiracles, often supplemented by increased convective flows driven by active body pumping). The diversity of insect respiratory patterns thus reflects complex interactions between (i) tracheal systems having to transition between configurations that support high versus low fluxes of oxygen and carbon dioxide, and (ii) differences in the physical and chemical characteristics of those gases.

\section{The diversity of respiratory patterns}

At rest, insects and other tracheate arthropods exhibit a fascinating diversity of gas exchange patterns (Marais et al., 2005; Chown et al., 2006; a simple schematic illustration is shown in Fig. 1). Chief among these are discontinuous gas exchange cycles (DGCs; see Glossary), which represent an extreme form of periodic or intermittent ventilation. Although DGCs have been recognized since the 1940s (see references in Punt et al., 1957), and have received considerable attention, they remain baffling. Because the DGC temporarily decouples the internal metabolic milieu from the external abiotic conditions, it is largely thought to facilitate metabolic homeostasis at the organismal level (Lighton, 1996). The main effector in this homeostasis feedback loop is the spiracle neuromuscular (valve) system (see Fig. 2 for some key concepts in DGC research) (e.g. Beckel and Schneiderman, 1957; reviewed in Matthews and Terblanche, 2015; Matthews, 2018). DGCs probably evolved from a simpler basal state characterized by more continuous or cyclic gas exchange (Marais et al., 2005). Remarkably, DGCs probably evolved at least three times independently in different classes of arthropods, and up to five times within insects themselves (Marais et al., 2005). Besides their occurrence in insects, DGCs have also been observed in myriapods (Klok et al., 2002) and various chelicerates (Lighton et al., 1993; Lighton and Fielden, 1995, 1996), two groups which evolved a terrestrial lifestyle, during the Paleozoic, independently of the terrestrialization of hexapods (Lozano-Fernandez et al., 2016).

Multiple gas exchange patterns are defined in the literature (see simple categories illustrated in Fig. 1). Broadly, these depend on the choice of measurement technique (i.e. direct versus indirect, tracheal partial pressures, direct spiracle observation, or $\mathrm{CO}_{2} / \mathrm{O}_{2}$ recording via respirometry) and the method of classification (i.e. how analyser or system noise is accounted for). An overview of the 


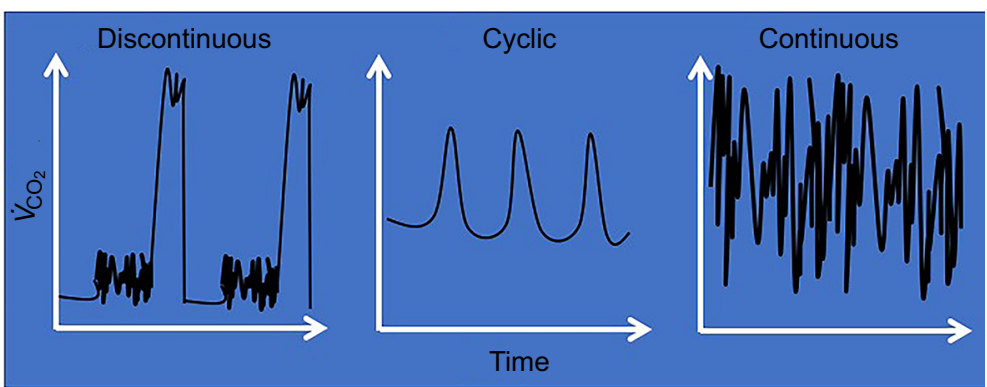

Fig. 1. Schematic illustration of three major respiratory patterns (discontinuous, cyclic or continuous gas exchange) recognized in the insect gas exchange literature. The illustration shows the patterns as they might be detected in a flow-through respirometry trace of $\mathrm{CO}_{2}$ production on a single individual insect. main methods and approaches in use, and the parameters measured to describe pattern variation, is given in Table 1 . Probably the most easily defined pattern is the DGC as it is characterized by distinct prolonged periods of spiracle closure, and hence the absence of gas exchange (i.e. zero $\mathrm{CO}_{2}$ emission, unless there is significant transcuticular gas exchange; e.g. Groenewald et al., 2012). The typical DGC pattern has a specific sequence of phases based on spiracle behaviour (see Glossary): closed (C) phase $\rightarrow$ flutter (F) phase $\rightarrow$ open $(\mathrm{O})$ phase. The pattern repeats regularly in this order, although some authors disregard that definition, instead preferring to focus on the amount of time spiracles are open or closed (e.g. Gray and Bradley, 2006; Contreras and Bradley, 2009). Regular or
A

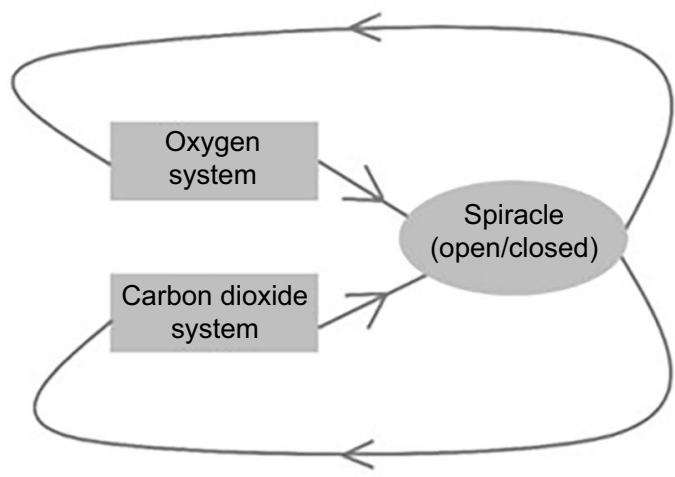

C

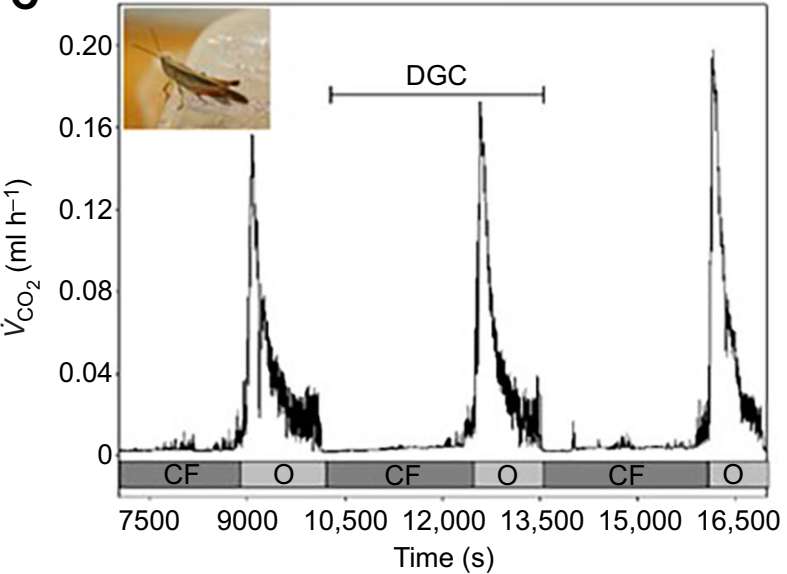

B

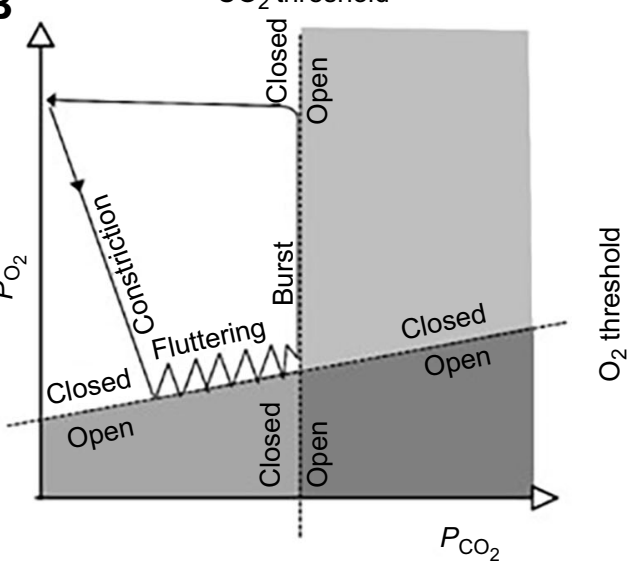

D

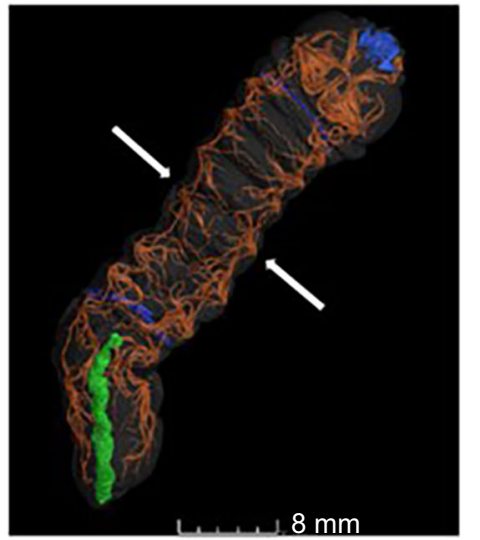

Fig. 2. Key concepts in insect discontinuous gas exchange cycles (DGCs). (A) The main theoretical effector of variability in whole-animal gas exchange, the spiracle neuromuscular valve system, is thought to be controlled by interacting feedback loops between oxygen- and carbon dioxide-sensing systems (redrawn from Grieshaber and Terblanche, 2015). (B) The oxygen-carbon dioxide phase space model of DGC proposed by Förster and Hetz (2010), which tracks the phases of the DGC cycle as a loop from the top left-hand corner, down towards the bottom left corner, then out towards the right-hand side and then back to the point of origin as the DGC proceeds through the 'constriction' (or 'closed'), 'flutter' and 'open' spiracle phases, respectively. (C) An example DGC trace taken from Groenewald et al. (2014) for a resting Paracinema tricolor grasshopper (inset) measured at $15^{\circ} \mathrm{C}$ via flow-through respirometry. The closed (C) and flutter (F) phases are treated together as a single unit and marked as 'CF' for simplicity. The CF and open (O) phases are marked respectively, according to the original source. (D) The three-dimensional structure of a representative tracheal respiratory system for a beetle larva. This image shows a high-resolution micro-computed tomography $(\mu \mathrm{CT})$ scan of a longhorn beetle (Cerambycidae) 5th instar larva performed at the Central Analytical Facilities at Stellenbosch University. The respiratory system is highlighted in orange and spiracles and atria can be readily seen (examples marked by white arrows). The mouthparts (blue) and hindgut (green) are also visible. At least seven pairs of spiracles are visible. 
Table 1. Diverse examples of studies and approaches employed in insect gas exchange pattern research

\begin{tabular}{|c|c|c|c|c|}
\hline $\begin{array}{l}\text { Parameter measured to monitor } \\
\text { gas exchange pattern }\end{array}$ & Main technique employed & $\begin{array}{l}\text { Experimental manipulation/main source of } \\
\text { variation }\end{array}$ & Study species & Source \\
\hline$\dot{\mathrm{V}}_{\mathrm{CO}_{2}}$ & $\begin{array}{l}\text { Flow-through respirometry } \\
\dot{V}_{\mathrm{CO}_{2}}\end{array}$ & Temperature & Many & Many \\
\hline$\dot{V}_{\mathrm{CO}_{2}}$ & Flow-through respirometry & Humidity & Aquarius remigis & $\begin{array}{l}\text { Contreras and } \\
\text { Bradley (2011) }\end{array}$ \\
\hline$\dot{V}_{\mathrm{CO}_{2}}$ & Flow-through respirometry & Ambient $\mathrm{O}_{2} / \mathrm{CO}_{2} /$ humidity & Nauphoeta cinerea & $\begin{array}{l}\text { Schimpf et al. } \\
(2009)\end{array}$ \\
\hline$\dot{V}_{\mathrm{CO}_{2}}+$ tracheal pressure & $\begin{array}{l}\text { Flow-through respirometry+ } \\
\text { tracheal pressure }\end{array}$ & Ambient $\mathrm{O}_{2} / \mathrm{CO}_{2} /$ humidity & Samia cynthia & $\begin{array}{l}\text { Terblanche et al. } \\
(2008)\end{array}$ \\
\hline$\dot{V}_{\mathrm{CO}_{2}}$ & Flow-through respirometry & Air flow rate & Glossina spp. & $\begin{array}{l}\text { Terblanche and } \\
\text { Chown (2010) }\end{array}$ \\
\hline$\dot{V}_{\mathrm{CO}_{2}}$ & Flow-through respirometry & Spiracle blocking/ontogeny & Samia cynthia & Hetz (2007) \\
\hline$\dot{\mathrm{V}}_{\mathrm{CO}_{2}}$ & Flow-through respirometry & Ambient $\mathrm{O}_{2}$ /ontogeny & Locusta migratoria & $\begin{array}{l}\text { Snelling et al. } \\
(2012 a, b)\end{array}$ \\
\hline $\begin{array}{l}\dot{V}_{\mathrm{CO}_{2}} \text {, tracheal } P_{\mathrm{O}_{2}} \text {, haemolymph } \\
\mathrm{pH}\end{array}$ & $\begin{array}{l}\text { Flow-through respirometry+ } \\
\text { optodes }\end{array}$ & Ambient $\mathrm{O}_{2} /$ decapitation & Nauphoeta cinerea & $\begin{array}{l}\text { Matthews and } \\
\text { White (2011) }\end{array}$ \\
\hline Ventilation rate & $\begin{array}{l}\text { Visual observation of } \\
\text { ventilatory frequency }\end{array}$ & $\begin{array}{l}\text { Injection of } \mathrm{NaOH}, \mathrm{NaHCO}_{3} \text { or } \mathrm{NaCl} \text { into } \\
\text { haemolymph, or } \mathrm{O}_{2} / \mathrm{CO}_{2} \text { into tracheae }\end{array}$ & $\begin{array}{l}\text { Romalea guttata, } \\
\text { Schistocerca gregaria }\end{array}$ & $\begin{array}{l}\text { Gulinson and } \\
\text { Harrison (1996) }\end{array}$ \\
\hline$\dot{V}_{\mathrm{CO}_{2}} / \mathrm{ROS}$ & $\begin{array}{l}\text { Flow-through respirometry+ } \\
\text { fluorescence microscopy }\end{array}$ & Ambient $\mathrm{O}_{2}$ levels & Samia cynthia & $\begin{array}{l}\text { Boardman et al. } \\
(2012)\end{array}$ \\
\hline$\dot{V}_{\mathrm{CO}_{2}}$ & Flow-through respirometry & Direct brain cooling with Peltier probe & Nauphoeta cinerea & $\begin{array}{l}\text { Matthews and } \\
\text { White (2013) }\end{array}$ \\
\hline$\dot{V}_{\mathrm{CO}_{2}} /$ respiratory structure & $\begin{array}{l}\text { Flow-through respirometry+ } \\
\text { staining }\end{array}$ & Ambient $\mathrm{O}_{2}$ levels & Nauphoeta cinerea & Bartrim et al. (2014) \\
\hline$\dot{V}_{\mathrm{CO}_{2}}$ & Flow-through respirometry & Immersion in water & Manduca sexta & $\begin{array}{l}\text { Woods and Lane } \\
(2016)\end{array}$ \\
\hline$\dot{V}_{\mathrm{CO}_{2}} /$ respiratory structure & $\begin{array}{l}\text { Flow-through respirometry+ } \\
\mu \mathrm{CT} \text { scan }\end{array}$ & Diving duration & Paracinema tricolor & $\begin{array}{l}\text { Gudowska et al. } \\
(2016)\end{array}$ \\
\hline$\dot{V}_{\mathrm{CO}_{2}} /$ respiratory structures & $\begin{array}{l}\text { Flow-through respirometry+ } \\
\text { X-ray synchrotron }\end{array}$ & Respiratory pattern & Pterostichus stygicus & Socha et al. (2008) \\
\hline Relative spiracle opening & Pressure gradient & $\begin{array}{l}\text { Perfusion by mixtures of different } \\
\text { levels of } \mathrm{O}_{2} \text { and } \mathrm{CO}_{2}\end{array}$ & Attacus atlas & $\begin{array}{l}\text { Förster and Hetz } \\
(2010)\end{array}$ \\
\hline $\begin{array}{l}\dot{V}_{\mathrm{CO}_{2}}, \text { EMG of spiracle closer } \\
\text { muscles }\end{array}$ & $\begin{array}{l}\text { Flow-through respirometry+ } \\
\text { direct nerve EMG signal }\end{array}$ & Respiratory pattern, ambient $\mathrm{O}_{2}$ levels & $\begin{array}{l}\text { Schistocerca gregaria, } \\
\text { Locusta migratoria }\end{array}$ & Talal et al. (2018) \\
\hline
\end{tabular}

The table shows common gas exchange parameters measured to describe variation in discontinuous gas exchange cycles (or other gas exchange patterns) in insects, a description of the main measurement technique, the primary experimental manipulation or source of variation used to probe gas exchange responses, the focal species examined, and an example source reference of each.

ROS, reactive oxygen species; $\mu \mathrm{CT}$, micro-computed tomography; EMG, electromyogram.

periodic patterns, such as cyclic gas exchange or DGC, are perhaps more easily identified than irregular, more chaotic signals especially in a noisy and/or time-lagged system (Pendar et al., 2016). In noisy systems, it often is unclear whether the noise arises from the actions of the animal or from some kind of experimental or methodological noise. Advances in time-series analysis have hardly made in-roads into insect respiratory pattern identification and classification, despite their widespread use in other areas of vertebrate respiration pattern research (Coelho et al., 2003; Levine et al., 2004; Adams et al., 1978). Here, for simplicity, we refer to three broad insect respiratory gas exchange patterns, which lie along an axis characterizing whether the insect closes its spiracles some or most of the time and, if so, whether patterns of closure are periodic. Thus the three patterns can be defined as: (i) DGC, possessing the three clear spiracle phases $(\mathrm{C}, \mathrm{F}, \mathrm{O})$, characterized by a prolonged spiracle closure (C-phase) period; (ii) 'cyclic' (see Glossary), where mainly spiracles are open but consisting of regular bursts of gas exchange and no prolonged spiracle closure (for an example, see Boisseau et al., 2017); and (iii) 'continuous' gas exchange (see Glossary) in which spiracles are mainly open, or at least they open and close so quickly as to produce an irregular pattern, and gas is emitted on average at a higher rate (Fig. 1; following convention adopted in Marais et al., 2005). There is one additional important axis: whether or not the insect relies primarily on diffusive gas transport or on some kind of forced ventilation of the tracheal system (e.g. Wasserthal, 1996; Talal et al., 2018; Heinrich et al., 2013).

Adding to the complexity, insects can transition between respiratory patterns depending on their physiological state and life stage. Furthermore, size plays an important role in the variation in cycle duration across species, probably partly driven by metabolic rate variation (Terblanche et al., 2008). For individuals, one of the most important factors appears to be metabolic rate (Contreras and 
Bradley, 2009, 2010). Individuals with low metabolic rates - either because their body temperatures are low or because they are inactive or they have not recently fed - often show DGC, whereas individuals with higher metabolic rates abandon DGC and use cyclic or continuous ventilation instead. The distribution of gas exchange patterns across life stages is less well known. In a handful of taxa (e.g. Orthoptera, Coleoptera), DGC is known to occur in multiple life stages of the same species (e.g. Snelling et al., 2012b). Formal comparisons across multiple life stages of diverse taxa, however, are lacking.

Although the diversity of insect patterns of gas exchange has been known for decades, we still have no unifying, general model that can explain it. This failure arises for several reasons but is linked most closely to the complexity of the problem: understanding transitions among modes of gas exchange will require integrating many parts from many levels of biological organization. Briefly, good models will have to incorporate realistic descriptions of the universal underlying biochemistry and physics of gas exchange, provide detailed and flexible descriptions of the evolved organismal parts that coordinate gas exchange (the sensors, neural patterning and muscular actions), and link those physical and physiological aspects convincingly to the ecological challenges faced by different lineages.

There are two fundamental levels of explanation that can be sought: one is to explain the evolutionary factors driving the evolution of DGC - a kind of 'ultimate causes' approach; another is to explain mechanistically what the important parts of any particular DGC system are, how they interact, and what kinds of emergent outputs the system can produce (i.e. inherent capacity or constraints). It may, however, be somewhat simplistic to take a reductionist approach to this problem by looking for single ultimate causes or to expect common mechanistic underpinnings across taxa, as these may vary by evolutionary history and taxon. Nevertheless, there still is something important here that requires explanation and, at the least, we need theories that can explain the repeated emergence of this complex phenomenon in multiple lineages of arthropods (Marais et al., 2005).

Why is it that DGC, and variation in insect respiratory patterns in general, has eluded explanation for so long? There are three main classes of potential 'failure' in modelling insect respiratory patterns. The first is that we have failed to identify some key component or process that underlies variation in respiratory patterns, including DGCs - although generally good, the models are incomplete in some fundamental way. A second potential failure is that we have identified all the key parts but have done a poor job of parameterizing them. More experimental physiology will contribute to resolving this possibility. A third and more difficult potential failure is that we have identified all the parts and have relatively good estimates of key parameters but have failed to interconnect parts or modules correctly. This last possibility is a tracheal-specific way of saying that respiratory patterns may be emergent properties of complex networks of interacting parts and modules (Chown and Holter, 2000; Aderem, 2005; Bizzarri et al., 2013; Martin et al., 2014). Work examining tuneable networks - i.e. complex metabolic systems that can be redirected to alternative, specific purposes - indicates that they probably possess different properties compared with nontuneable networks and, at least in some cases, the complexity of these tuneable networks has distinct advantages for cellular regulation and homeostasis (e.g. Tsai et al., 2008).

Table 2. Adaptive and non-adaptive explanations proposed for DGCs and pattern transitions

\begin{tabular}{|c|c|c|c|c|}
\hline Type & $\begin{array}{l}\text { Pattern } \\
\text { explained }\end{array}$ & Hypothesis/name & Main argument & Source $^{a}$ \\
\hline \multirow[t]{8}{*}{ Adaptive } & DGC & Hygric & $\begin{array}{l}\text { Respiratory water savings drive DGC evolution; spiracle } \\
\text { closure saves respiratory water. }\end{array}$ & Buck et al. (1953) \\
\hline & DGC & Oxidative damage & $\begin{array}{l}\text { Oxidative damage potentially caused by a highly } \\
\text { conductive respiratory system, especially when at low } \\
\text { metabolic demand, drives regulation of a low } P_{\mathrm{O}_{2}} \text { set } \\
\text { point. }\end{array}$ & $\begin{array}{l}\text { Bradley }(2000) \\
\text { Hetz and Bradley } \\
(2005)\end{array}$ \\
\hline & DGC & Chthonic & $\begin{array}{l}\text { DGC facilitates gas exchange in subterranean } \\
\text { environments by increasing concentration gradients of } \\
\mathrm{CO}_{2} \text { and } \mathrm{O}_{2} \text {. }\end{array}$ & $\begin{array}{l}\text { Lighton and } \\
\text { Berrigan (1995) }\end{array}$ \\
\hline & DGC & Hygric-chthonic & $\begin{array}{l}\text { Evolution of DGC for subterranean gas exchange came } \\
\text { with the benefit of saving respiratory water. }\end{array}$ & $\begin{array}{l}\text { Gibbs and } \\
\text { Johnson (2004) }\end{array}$ \\
\hline & DGC & Strolling arthropod & $\begin{array}{l}\text { Spiracle closure restricts entry of mites and reduces } \\
\text { infestations. }\end{array}$ & Miller (1974) \\
\hline & All & Metabolic demand & $\begin{array}{l}\text { Metabolic rate is a key driver of transitions among } \\
\text { respiratory patterns. }\end{array}$ & $\begin{array}{l}\text { Contreras and } \\
\text { Bradley (2010) }\end{array}$ \\
\hline & All & Respiratory adequacy & $\begin{array}{l}\text { Transitions among types of ventilation reflect the balance } \\
\text { between metabolic consumption of oxygen and oxygen } \\
\text { availability in the tracheal system. }\end{array}$ & $\begin{array}{l}\text { Contreras and } \\
\text { Bradley (2009) }\end{array}$ \\
\hline & DGC (all) & Conductance/metabolic state & $\begin{array}{l}\text { Trade-offs between metabolic rate and spiracle } \\
\text { conductance determine pattern transitions. }\end{array}$ & $\begin{array}{l}\text { Moerbitz and Hetz } \\
(2010)\end{array}$ \\
\hline \multirow[t]{2}{*}{ Non-adaptive } & DGC & Interacting set points/emergent properties & $\begin{array}{l}\text { DGC is a product of oscillation between } P_{\mathrm{O}_{2}} \text { and } \\
P_{\mathrm{CO}_{2}} \text { homeostasis set points. }\end{array}$ & $\begin{array}{l}\text { Chown and Holter } \\
(2000)\end{array}$ \\
\hline & DGC & Neural & $\begin{array}{l}\text { During low brain activity, the peripheral nervous system } \\
\text { takes over control of respiratory patterns from the central } \\
\text { nervous system. }\end{array}$ & $\begin{array}{l}\text { Matthews and } \\
\text { White (2010) }\end{array}$ \\
\hline
\end{tabular}




\section{Evolutionary explanations of pattern diversity}

Early reviews focused on how the presence of DGCs was related to morphology and taxonomic diversity (Miller, 1974), and the effects of abiotic factors in subterranean environments (e.g. hypoxia, hypercapnia; see Glossary) or deserts (e.g. low water availability or high temperatures) (e.g. Lighton, 1996, 1998) (Table 2). Oxygen toxicity - or specifically the need to avoid oxygen free radical damage that might be associated with a high-conductance respiratory system when in a low metabolic demand state - also arose as a major novel explanation for the evolution of discontinuous gas exchange (Hetz and Bradley, 2005; see also Boardman et al., 2012). There has also been renewed attention paid to the interaction between tracheal morphology and overall respiratory conductance, and how the interaction between metabolic demand and respiratory system constraints might influence the gas exchange pattern and transitions among spiracle states (e.g. Hetz, 2007; Moerbitz and Hetz, 2010), and such approaches are aided by the ease with which tracheal and whole-animal morphology can be rapidly imaged through, for example, micro-computed tomography $(\mu \mathrm{CT})$ scans (see Glossary; Fig. 2D; and see Du Plessis et al., 2017, for recommendations on best practice). Transmission (TEM) and scanning electron microscopy (SEM) can perhaps more readily image the terminal tracheoles $( \pm 0.5$ to $2 \mu \mathrm{m})$, the primary site of gas exchange within the tissue (e.g. Schmitz and Perry, 1999), although this will probably vary with the size of the focal organism. Recent reviews have increasingly considered the roles of the neural system and haemolymph acid-base regulation, but especially transitions in respiratory control between central and peripheral nervous systems occurring during periods of low brain activity (e.g. Matthews, 2018). These later reviews also consider in detail the possible interactions between spiracle states and various internal conditions (e.g. haemolymph $\mathrm{pH}, P_{\mathrm{O}_{2}}$ ) and external factors (e.g. temperature, gas composition) (Matthews and Terblanche, 2015; Matthews, 2018) that together may influence patterns of gas exchange and metabolic regulation.

There is a suite of adaptive and non-adaptive explanations proposed for DGCs and for pattern transitions in tracheate arthropods more generally (Table 1), and this has been the focus of several previous reviews (e.g. Chown et al., 2006; Contreras et al., 2014). We therefore keep this section brief but encourage readers to consult these earlier benchmark reviews. Discontinuous gas exchange may be an adaptive solution to fundamental respiratory challenges in diverse terrestrial environments (e.g. xeric or fossorial; see Glossary), but to understand the extent and magnitude of pattern variability, even if its origin is non-adaptive, remains a notable challenge to evolutionary comparative and respiratory physiologists. It is incumbent that the diversity of patterns - and the responses of insects more broadly to an array of stressors, including variation in temperature, moisture, oxygen, carbon dioxide and interactions thereof - be explained. A key challenge is to produce models that successfully predict the relationship between the presence or absence of particular respiratory patterns and the specific ecological and physiological circumstances of individual lineages.

Such an understanding may also have wide-ranging practical applications. For example, the insect tracheal system has inspired biomimetic approaches to microfluidics; Aboelkassem and Staples (2013) used observations and data on contractions of insect tracheae to develop models of selective pumping of fluids in complex networks of tubes. Understanding patterns of ventilation - and the consequences for gas-water trade-offs - will be important in developing mechanistic models capable of predicting insect responses to climate change risk (see discussions in e.g. Helmuth et al., 2005; Verberk et al., 2016). Finally, patterns of ventilation can affect the efficacy of insecticides. In particular, elevated levels of $\mathrm{CO}_{2}$ can be used to induce more frequent spiracular opening, which can enhance the lethality of gaseous insecticides (Jones, 1938). In addition, patterns of ventilation can be altered by botanically produced toxins (Harak et al., 1999; Sibul et al., 2004), which may alter the rate of oxygen supply to support activity or rates of water loss. Developing a stronger mechanistic basis for understanding and predicting such effects will depend on developing better general models of respiratory transitions.

\section{Proximate explanations of diversity}

Two major physiological processes are thought to underlie DGC: either endotracheal $\mathrm{CO}_{2}$ exceeding a particular partial pressure or $\mathrm{O}_{2}$ falling below a partial pressure that, in each case, triggers the opening of the spiracles (Burkett and Schneiderman, 1974; Förster and Hetz, 2010). Briefly, the C-phase involves a prolonged depletion of $\mathrm{O}_{2}$ stored mainly in the tracheal system while $\mathrm{CO}_{2}$ is simultaneously accumulated and buffered in the haemolymph. Eventually, $\mathrm{O}_{2}$ levels fall below the threshold and this causes the spiracle to flutter. At this point, there is still some $\mathrm{CO}_{2}$-buffering capacity available, and the $\mathrm{CO}_{2}$ threshold has not yet been reached. When the $\mathrm{CO}_{2}$ threshold is subsequently exceeded, the spiracles open fully (O-phase), and $\mathrm{CO}_{2}$ offloading is often supplemented with active body contractions (ventilation). The O-phase rapidly restores internal body and endotracheal stores of oxygen, but the accumulated (buffered) $\mathrm{CO}_{2}$ takes longer to return to acceptable levels. Once $\mathrm{CO}_{2}$ falls to acceptable levels, the $\mathrm{C}$-phase can begin again and the cycle repeats. The identity and location of the $P_{\mathrm{O}_{2}}$ and $P_{\mathrm{CO}_{2}}$ sensors (see Glossary), their precise mode of action (e.g. $\mathrm{pH}$ versus $\left.P_{\mathrm{CO}_{2}}\right)$, and their potential interaction are the subject of ongoing debate and interest (Förster and Hetz, 2010; Grieshaber and Terblanche, 2015; Matthews and Terblanche, 2015).

Despite a rich history of theoretical models analysing gas exchange by insects (see Pickard, 1974, and references therein; Table 3), dating to early seminal work by Krogh (1920) and Wigglesworth (1935) on respiratory structures and their diversity, only later were comprehensive models of respiratory water loss developed by Kestler (1985). More recently, these have been extended to deal specifically with the dynamics of respiratory water loss at the spiracle (Simelane et al., 2014) or at the whole-animal level (Woods and Smith, 2010) and the latter was supported by a comprehensive null model developed from first principles of diffusive gas exchange. A non-exhaustive literature survey highlights that several approaches and types of models can be readily differentiated (Table 3), from hypothetical (e.g. Chown and Holter, 2000) to computational and hybrid blends of simulations and analytical approaches. Recent models have become more complex, probably owing in part to increased computational power and reductions of personal computer costs, but partly also to a growing appreciation of the mechanistic underpinning and physiological details (e.g. Grieshaber and Terblanche, 2015). Some models tackle variation among respiratory patterns directly, whereas others simply aim to explain the fluxes of major gases $\left(\mathrm{CO}_{2}, \mathrm{O}_{2}, \mathrm{H}_{2} \mathrm{O}\right)$ in some specific part(s) of the insect respiratory system [e.g. in the tracheae (Simelane et al., 2014) or across the spiracles as a function of varying cross-sectional area (Snyder et al., 1995)]. Models are in some cases purely mathematical or hypothetical (e.g. Kestler, 1985) but in other cases use a combination of physico-chemical modelling and experimentation (e.g. Förster and Hetz, 2010). Yet others are numerical simulations 
Table 3. History and features of models of insect gas exchange (generally) and pattern variability or DGC (specifically)

\begin{tabular}{llll}
\hline Type & Main elements & Pros & Cons \\
\hline $\begin{array}{l}\text { Theoretical/ } \\
\text { mathematical }\end{array}$ & Diffusion of $\mathrm{O}_{2}$ along insect & Offers convincing diffusion-based & Applies primarily to tracheolar \\
& tracheoles. & explanation for lower limits on & function, not to the tracheal system \\
tracheolar diameters. & & generally.
\end{tabular}

Theoretical/

hypothetical

Theoretical calculations from first principles of chemistry and physics.

Theoretical

Diffusive and convective uptake of $\mathrm{O}_{2}$ and loss of water.

Conceptual, computational and experimental

Theoretical and computational

Dynamics of $\mathrm{O}_{2}, \mathrm{CO}_{2}$ and $\mathrm{H}_{2} \mathrm{O}$ transport across the spiracle.

Computational

Interacting feedback loops for $P_{\mathrm{CO}_{2}}$ and $P_{\mathrm{O}_{2}}$ systems.
Spiracular opening and closing in relation to internal levels of $\mathrm{O}_{2}$ and $\mathrm{CO}_{2}$.
Focused on tracheal/spiracular morphology and how site or

Pumping of gases inside tracheal networks. scaling might be affected by

Explains how modification of spiracle cross-sectional area can regulate respiratory water loss and under which conditions such variation should make the most difference.

Three different models for each phase of DGC employed; detailed assessment of morphological influence on meeting metabolic demand across normoxia and hypoxia.

Numerical approaches to modelling selective pumping of gases in a tracheal-like network of tubes. Integrates modern observations on tracheal compressibility and internal gas transport.

Provides a simple model for water loss and respiratory gas exchange through tubes of all kinds (including the insect tracheal system); possible to parameterize for diffusive or convective exchange.

Detailed model of dual control of spiracular state by internal levels of $\mathrm{O}_{2}$ and $\mathrm{CO}_{2}$; conceptual model proposed that accounts for all phases of DGC; Förster (2010) contains, in addition, detailed mathematical models of spiracular fluttering and the $\mathrm{CO}_{2}$ cycle.

A broad exploration of the sensitivity of spiracular state to internal and external gas concentrations; includes explicit interactions among the three gases; formulates gas exchange equations in terms of Lotka-Volterra dynamics (see Glossary).

Finite elements approach; various trigger sets considered; some trigger sets could reproduce several elements of DGCs so long as the model included hysteresis in one feedback loop.

Dynamics of gas flow during DGC. Detailed assessment of tracheal gas flow during DGC.
Largely only cockroach empirical data; focused on the problem of water loss, although more recent work has identified other potential adaptive and non-adaptive factors.

No explicit consideration of physiological feedbacks or model for transitions between phases of DGC Also focused primarily on water loss as the key cost.

Concerned primarily with internal transport of gases rather than the transport phenomena and spiracular mechanisms connecting internal and environmental conditions.

Ignores much physiological and neural detail about how insects control gas traffic. Not focused on spiracular control. Focused primarily on water loss as a cost.

Focused on spiracular control but no comprehensive coverage of intratracheal transport mechanisms; data derived primarily from pupae of a single moth species.

Like many models, uses minimization of water loss as a key criterion. Model contains a large number of parameters, some of them difficult to visualize.

Only realistic outputs under specific conditions - unclear how relevant or reliable these assumptions were.

Grieshaber and Terblanche (2015)

Ignored mechanisms producing DGC. Simelane et al. (2016) with diverse sets of thresholds ('trigger sets') and parameters considered in sub-sets of potential combinations (Grieshaber and Terblanche, 2015). One limitation of this last type of model is that to fully explore multi-parameter phase spaces is computationally daunting and experimentally time consuming. Consequently, these model types frequently use a combination of a priori expectations and subjective intuition to streamline the simulation process.

The major failure thus far in these models is that even the most complex, detailed computational model is capable of generating DGC-like patterns only under specific conditions and typically only for restricted sets of model organisms and scenarios. By contrast, in these cases the models have succeeded in producing realistic physical outputs from biologically realistic ranges of parameter values (e.g. Grieshaber and Terblanche, 2015), and can thus be used to explore plausible, albeit simple, scenarios (e.g. transitions in patterns between low versus high metabolic rates, pattern response to alterations in gas composition). Few models attempt to understand evolved pattern variation and its potential adaptive significance despite the evolutionary and ecological significance of such an approach. These extend beyond simply understanding a localized phenomenon 
as they may provide insights into how animals can tune respiratory gas exchange to meet aerobic cellular demands while understanding potential physiological or fitness costs of different solutions to a common problem (energy homeostasis) (see e.g. Tsai et al., 2008). This, in conjunction with understanding any potential mechanical or mechanistic constraints on a particular respiratory system, may provide greater understanding of any possible trade-offs that are likely to be fundamental to the evolution of respiratory systems.

\section{Paths forward}

Explaining the diversity of insect respiratory patterns is a key unsolved problem that spans the fields of biophysics, physiology, evolution and ecology. Successful explanations will necessarily be highly integrative. Two broad classes of integration are required. First, mechanistic models should be built from the fundamental aspects of transport and chemistry related to the general principles presented above ('fundamentals') but also should contain sufficient physiological detail that the general model can be altered in realistic ways to produce the entirety of the observed patterns of exchange, both within individuals and across species (e.g. Marais et al., 2005). A second kind of powerful integration would be to put together adaptive evolutionary hypotheses and physical/physiological process-based models. To date, such an approach has been largely overlooked. In other words, a 'general model' should be able to give insight into when lineages will emphasize one currency over another (e.g. controlling oxygen levels versus saving water; see discussion in Groenewald et al., 2014), when the same pattern (DGC) varies (e.g. in duration) among species living in different environments (e.g. White et al., 2007) or responds to changing conditions via plastic physiological adjustments (e.g. Terblanche et al., 2010). Generalized species-specific models could be useful if they can capture differences among species.

Several obvious questions can readily be tackled using such an approach. First, how many ways - mechanistically - can one observe the same respiratory outcome? Second, are there obvious ways of altering networks so that they reproduce the observed diversity of patterns? Third, are certain network configurations (e.g. a particular combination of neuronal and respiratory system morphology) more prone to evolve DGC-like respiration? Perhaps in silico evolution experiments should be attempted in which a starting 'lineage' is allowed to evolve in response to different combinations of fluctuating environmental stresses that mimic supposed conditions in most of the major adaptive explanations (changes in overall metabolic demand, highly desiccating environments, new combinations of gases that reflect underground conditions or specific paleoclimates, etc.) to ask whether physiology and patterns evolve in expected ways. To date, this approach has not been undertaken, but the opportunity clearly exists.

\section{Acknowledgements}

The authors are grateful to Michaela Handel and Julian Dow for the invitation to contribute this Commentary, and to the anonymous referees and David Hatton for providing constructive feedback on an earlier draft. J.S.T. thanks Chantelle Smit for assistance preparing figures and the bibliography and Anton du Plessis at Central Analytical Facilities for tracheal imaging.

\section{Competing interests}

The authors declare no competing or financial interests.

\section{References}

Aboelkassem, Y. and Staples, A. E. (2013). Selective pumping in a network: insect-style microscale flow transport. Bioinspir. Biomim. 8.

Adams, J. M., Attinger, E. O. and Attinger, F. M. (1978). Cluster analysis of respiratory time series. Biol. Cybern. 28, 183-190.
Aderem, A. (2005). Systems biology: its practice and challenges. Cell 121, 511-513. Bartrim, H., Matthews, P. G. D., Lemon, S. and White, C. R. (2014). Oxygeninduced plasticity in tracheal morphology and discontinuous gas exchange cycles in cockroaches Nauphoeta cinerea. J. Comp. Physiol. B. 184, 977-990

Beckel, W. E. and Schneiderman, H. A. (1957). Insect spiracle as an independent effector. Science 126, 352-353.

Bizzarri, M., Palombo, A. and Cucina, A. (2013). Theoretical aspects of Systems Biology. Prog. Biophys. Mol. Biol. 112, 33-43.

Boardman, L., Terblanche, J. S., Hetz, S. K., Marais, E. and Chown, S. L. (2012) Reactive oxygen species production and discontinuous gas exchange in insects. Proc. R. Soc. B 279, 893-901.

Boisseau, R. P., Woods, H. A. and Goubault, M. (2017). The metabolic costs of fighting and host exploitation in a seed-drilling parasitic wasp. J. Exp. Biol. 220, 3955-3966.

Bradley, T. (2000). The discontinuous gas exchange cycle in insects may serve to reduce oxygen supply to the tissues. Am. Zool. 40, 952.

Buck, J., Keister, M. and Specht, H. (1953). Discontinuous respiration in diapausing Agapema pupae. Anat. Rec. 117, 541-541.

Burkett, B. N. and Schneiderman, H. A. (1974). Roles of oxygen and carbon dioxide in the control of spiracular function in Cecropia pupae. Biol. Bull. 147 274-293.

Burmester, T. and Hankeln, T. (2007). The respiratory proteins of insects. J. Ins. Physiol. 53, 285-294.

Chown, S. L. (2002). Respiratory water loss in insects. Comp. Biochem. Physiol. A Mol. Integr. Physiol. 133, 791-804.

Chown, S. L. and Holter, P. (2000). Discontinuous gas exchange cycles in Aphodius Fossoe (Scarabaeidae): A test of hypotheses concerning origins and mechanism. J. Exp. Biol. 203, 397-403.

Chown, S. L., Gibbs, A. G., Hetz, S. K., Klok, C. J., Lighton, J. R. B. and Marais, E. (2006). Discontinuous gas exchange in insects: a clarification of hypotheses and approaches. Physiol. Biochem. Zool. 79, 333-343.

Coelho, F. C., Baker, T. L. and Smatresk, N. J. (2003). Ventilatory behaviors of the toad Bufo marinus revealed by coherence analysis. Braz. J. Biol. 63, 27-34.

Contreras, H. L. and Bradley, T. J. (2009). Metabolic rate controls respiratory pattern in insects. J. Exp. Biol. 212, 424-428.

Contreras, H. L. and Bradley, T. J. (2010). Transitions in insect respiratory patterns are controlled by changes in metabolic rate. J. Insect Physiol. 56, 522-528.

Contreras, H. L. and Bradley, T. J. (2011). The effect of ambient humidity and metabolic rate on the gas-exchange pattern of the semi-aquatic insect Aquarius remigis. J. Exp. Biol. 214, 1086-1091.

Contreras, H. L., Heinrich, E. C. and Bradley, T. J. (2014). Hypotheses regarding the discontinuous gas exchange cycle (DGC) of insects. Curr. Opin. Insect Sci. 4 48-53

Denny, M. W. (1993). Air and Water: The Biology and Physics of Life's Media. Princeton, USA. Princeton University Press.

Du Plessis, A., Broeckhoven, C., Guelpa, A. and Le Roux, S. G. (2017) Laboratory x-ray micro-computed tomography: a user guideline for biological samples. GigaScience 6, 1-11.

Dudley, R. (2002). The Biomechanics of Insect Flight: Form, Function, Evolution Princeton, USA. Princeton University Press.

Förster, T. D. (2010). Spiracular control in moth pupae: passive generation of respiratory patterns. PhD Dissertation, Berlin, Humboldt-University.

Förster, T. D. and Hetz, S. K. (2010). Spiracle activity in moth pupae - the role of oxygen and carbon dioxide revisited. J. Insect Physiol. 56, 492-501.

Gaston, K. J. (2003). The Structure and Dynamics of Geographic Ranges. Oxford UK: Oxford University Press.

Gibbs, A. G. and Johnson, R. A. (2004). The role of discontinuous gas exchange in insects: the chthonic hypothesis does not hold water. J. Exp. Biol. 207, 3477-3482.

Gray, E. M. and Bradley, T. J. (2006). Evidence from mosquitoes suggests that cyclic gas exchange and discontinuous gas exchange are two manifestations of a single respiratory pattern. J. Exp. Biol. 209, 1603-1611.

Greenlee, K. J. and Harrison, J. F. (1998). Acid-base and respiratory responses to hypoxia in the grasshopper Schistocerca americana. J. Exp. Biol. 201 2843-2855.

Greenlee, K. J., Henry, J. R., Kirkton, S. D., Westneat, M. W., Fezzaa, K., Lee, W. K. and Harrison, J. F. (2009). Synchrotron imaging of the grasshopper tracheal system: morphological and physiological components of tracheal hypermetry. Am. J. Physiol. Regul. Integr. Comp. Physiol. 297, R1343-R1350.

Grieshaber, B. J. and Terblanche, J. S. (2015). A computational model of insect discontinuous gas exchange: A two-sensor, control systems approach. J. Theo. Biol. 374, 138-151.

Grimaldi, D. and Engel, M. S. (2005). Evolution of the Insects. Cambridge, UK Cambridge University Press.

Groenewald, B., Hetz, S. K., Chown, S. L. and Terblanche, J. S. (2012) Respiratory dynamics of discontinuous gas exchange in the tracheal system of the desert locust, Schistocerca gregaria. J. Exp. Biol. 215, 2301-2307.

Groenewald, B., Chown, S. L. and Terblanche, J. S. (2014). A hierarchy of factors influence discontinuous gas exchange in the grasshopper, Paracinema tricolo (Orthoptera: Acrididae). J. Exp. Biol. 217, 3407-3415. 
Gudowska, A., Boardman, L. and Terblanche, J. S. (2016). The closed spiracle phase of discontinuous gas exchange predicts diving duration in the grasshopper Paracinema tricolor. J. Exp. Biol. 219, 2423-2425.

Gulinson, S. L. and Harrison, J. F. (1996). Control of resting ventilation rate in grasshoppers. J. Exp. Biol. 199, 379-389.

Harak, M., Lamprecht, I., Kuusik, A., Hiiesaar, K., Metspalu, L. and Tartes, U. (1999). Calorimetric investigations of insect metabolism and development under the influence of a toxic plant extract. Thermochimica acta 333, 39-48.

Harrison, J. F., Woods, H. A. and Roberts, S. P. (2012). Ecological and Environmental Physiology of Insects. Oxford, UK. Oxford University Press.

Heinrich, E. C., McHenry, M. J. and Bradley, T. J. (2013). Coordinated ventilation and spiracle activity produce unidirectional airflow in the hissing cockroach Gromphadorhina portentosa. J. Exp. Biol. 216, 4473-4482.

Helmuth, B., Kingsolver, J. G. and Carrington, E. (2005). Biophysics, physiological ecology, and climate change: does mechanism matter? Annu. Rev. Physiol. 67, 177-201.

Hetz, S. K. (2007). The role of the spiracles in gas exchange during development of Samia cynthia (Lepidoptera, Saturniidae). Comp. Biochem. Physiol. A 148, 743-754

Hetz, S. K. and Bradley, T. J. (2005). Insects breathe discontinuously to avoid oxygen toxicity. Nature 433, 516-519.

Hetz, S. K., Psota, E. and Wasserthal, L. T. (1999). Roles of aorta, ostia and tracheae in heartbeat and respiratory gas exchange in pupae of Troides rhadamantus Staudinger 1888 and Ornithoptera priamus L. 1758 (Lepidoptera, Papilionidae). Int. J. Insect Morph. 28, 131-144.

Jones, R. M. (1938). Toxicity of fumigant-CO2 mixtures to the red flour beetle J. Econ. Entomol. 31, 298-309.

Kestler, P. (1985). Respiration and respiratory water loss. In Environmental Physiology and Biochemistry of Insects (ed. K. H. Hoffmann), pp. 137-183. Berlin: Springer.

Klok, C. J., Mercer, R. D. and Chown, S. L. (2002). Discontinuous gas-exchange in centipedes and its convergent evolution in tracheated arthropods. J. Exp. Biol. 205, 1019-1029

Krogh, A. (1920). Studien über Tracheenrespiration. II. Uber Gasdiffusion in den Tracheen. Pfluger. Arch. Gesamte Physiol. Menschen Tiere 179, 95-112.

Lehmann, F.-O. (2001). Matching spiracle opening to metabolic need during flight in Drosophila. Science 294, 1926-1929.

Levine, M., Hathorn, M. and Cleave, J. (2004). Mathematical methods in the study of respiration in newborn babies. Cardiovas. Eng. 4, 133-138.

Lighton, J. R. B. (1996). Discontinuous gas exchange in insects. Annu. Rev. Entomol. 41, 309-324.

Lighton, J. R. B. (1998). Notes from underground: towards ultimate hypotheses of cyclic, discontinuous gas-exchange in tracheate arthropods. Am. Zool. 38, 483-491.

Lighton, J. R. B. (2007). Respiratory Biology: why insects evolved discontinuous gas exchange. Curr. Biol. 17, R645-R647.

Lighton, J. and Berrigan, D. (1995). Questioning paradigms: caste-specific ventilation in harvester ants, Messor pergandei and M. julianus (Hymenoptera: Formicidae). J. Exp. Biol. 198, 521-530.

Lighton, J. R. B. and Fielden, L. J. (1995). Mass scaling of standard metabolism in ticks: A valid case of low metabolic rates in sit-and-wait strategists. Physiol. Zool. 68, 43-62.

Lighton, J. R. B. and Fielden, L. J. (1996). Gas exchange in wind spiders (Arachnida, Solphugidae): Independent evolution of convergent control strategies in solphugids and insects. J. Insect Physiol. 42, 347-357.

Lighton, J. R. B., Fielden, L. J. and Rechav, Y. (1993). Discontinuous ventilation in a non-insect, the tick Amblyomma marmoreum (Acari: Ixodidae): characterization and metabolic modulation. J. Exp. Biol. 180, 229-245.

Lozano-Fernandez, J., Carton, R., Tanner, A. R., Puttick, M. N., Blaxter, M., Vinther, J., Olesen, J., Giribet, G., Edgecombe, G. D. and Pisani, D. (2016). A molecular palaeobiological exploration of arthropod terrestrialization. Philos. Trans. R. Soc. B Biol. Sci. 371, 20150133.

Marais, E., Klok, C. J., Terblanche, J. S. and Chown, S. L. (2005). Insect gas exchange patterns: a phylogenetic perspective. J. Exp. Biol. 208, 4495-4507.

Martin, L. B., Ghalambor, C. K. and Woods, H. A. (2014). Integrative Organismal Biology. Hoboken, NJ: John Wiley \& Sons.

Matthews, P. G. D. (2018). The mechanisms underlying the production of discontinuous gas exchange cycles in insects. J. Comp. Physiol. B 188, 195-210.

Matthews, P. G. D. and Terblanche, J. S. (2015). Evolution of the mechanisms underlying insect respiratory gas exchange. Adv. Insect Physiol. 49, 1-24.

Matthews, P. G. D. and White, C. R. (2010). Discontinuous gas exchange in insects: is it all in their heads? Am. Nat. 177, 130-134.

Matthews, P. G. D. and White, C. R. (2011). Regulation of gas exchange and haemolymph $\mathrm{pH}$ in the cockroach Nauphoeta cinerea. J. Exp. Biol. 214 3062-3073

Matthews, P. G. D. and White, C. R. (2013). Reversible brain inactivation induces discontinuous gas exchange in cockroaches. J. Exp. Biol. 216, 2012-2016.

Miller, P. L. (1966). The regulation of breathing in insects. Adv. Insect Physiol. 3, 279-354
Miller, P. L. (1974). Respiration-aerial gas transport. In The Physiology of Insecta 2nd edn. (ed. M. Rockstein), pp. 345-402. New York: Academic Press.

Moerbitz, C. and Hetz, S. K. (2010). Tradeoffs between metabolic rate and spiracular conductance in discontinuous gas exchange of Samia cynthia (Lepidoptera, Saturniidae). J. Insect Physiol. 56, 536-542.

Pendar, H., Socha, J. J. and Chung, J. (2016). Recovering signals in physiological systems with large datasets. Biol. Open 5, 1163-1174.

Pickard, W. F. (1974). Transition regime diffusion and the structure of the insect tracheolar system. J. Insect Physiol. 20, 947-956.

Punt, A., Parser, W. J. and Kuchlein, J. (1957). Oxygen uptake in insects with cyclic CO2 release. Biol. Bull. 112, 108-119.

Scheipers, G., Kawashiro, T. and Scheid, P. (1975). Oxygen and carbon dioxide dissociation of duck blood. Resp. Physiol. 24, 1-13.

Schimpf, N. G., Matthews, P. G. D., Wilson, R. S. and White, C. R. (2009) Cockroaches breathe discontinuously to reduce respiratory water loss. J. Exp. Biol. 212, 2773-2780.

Schmidt-Nielsen, K. (1997). Animal Physiology: Adaptation and Environment, 5th edn. Cambridge, UK. Cambridge University Press.

Schmitz, A. and Perry, S. F. (1999). Stereological determination of tracheal volume and diffusing capacity of the tracheal walls in the stick insect Carausius morosus (Phasmatodea, Lonchodidae). Physiol. Biochem. Zool. 72, 205-218.

Sibul, I., Kuusik, A. and Voolma, K. (2004). Monitoring of gas exchange cycles and ventilatory movements in the pine weevil Hylobius abietis: respiratory failures evoked by a botanical insecticide. Ent. Exp. Appl. 110, 173-179.

Simelane, S. M., Abelman, S. and Duncan, F. D. (2014). Dynamics of the oxygen, carbon dioxide, and water interaction across the insect spiracle. Abs. Appl. Anal. 2014, 157573

Simelane, S. M., Abelman, S. and Duncan, F. D. (2016). Gas exchange models for a flexible insect tracheal system. Acta Biotheor. 64, 161-196.

Snelling, E. P., Seymour, R. S., Runciman, S., Matthews, P. G. D. and White C. R. (2011). Symmorphosis and the insect respiratory system: allometric variation. J. Exp. Biol. 214, 3225-3237.

Snelling, E. P., Seymour, R. S., Runciman, S., Matthews, P. G. D. and White C. R. (2012a). Symmorphosis and the insect respiratory system: a comparison between flight and hopping muscle. J. Exp. Biol. 215, 3324-3333.

Snelling, E. P., Matthews, P. G. D. and Seymour, R. S. (2012b). Allometric scaling of discontinuous gas exchange patterns in the locust Locusta migratoria throughout ontogeny. J. Exp. Biol. 215, 3388-3393.

Snyder, G. K., Sheafor, B., Scholnick, D. and Farrelly, C. (1995). Gas exchange in the insect tracheal system. J. Theor. Biol. 172, 199-207.

Socha, J. J., Lee, W.-K., Harrison, J. F., Waters, J. S., Fezzaa, K. and Westneat M. W. (2008). Correlated patterns of tracheal compression and convective gas exchange in a carabid beetle. J. Exp. Biol. 211, 3409-3420.

Socha, J. J., Forster, T. D. and Greenlee, K. J. (2010). Issues of convection in insect respiration: insights from synchrotron X-ray imaging and beyond. Respir. Physiol. Neurobiol. 173, S65-S73.

Talal, S., Gefen, E. and Ayali, A. (2018). Intricate but tight coupling of spiracula activity and abdominal ventilation during locust discontinuous gas exchange cycles. J. Exp. Biol. 221.

Terblanche, J. S. and Chown, S. L. (2010). Effects of flow rate and temperature on cyclic gas exchange in tsetse flies (Diptera, Glossinidae). J. Insect Physiol. 56, 513-521.

Terblanche, J. S., White, C. R., Blackburn, T. M., Marais, E. and Chown, S. L. (2008). Scaling of gas exchange cycle frequency in insects. Biol. Lett. 4, 127-129. Terblanche, J. S., Clusella-Trullas, S. and Chown, S. L. (2010). Phenotypic plasticity of gas exchange pattern and water loss in Scarabaeus spretus (Coleoptera: Scarabaeidae): deconstructing the basis for metabolic rate variation. J. Exp. Biol. 213, 2940-2949.

Timmins, G. S., Robb, F. J., Wilmot, C. M., Jackson, S. K. and Swartz, H. M. (2001). Firefly flashing is controlled by gating oxygen to light-emitting cells. J. Exp. Biol. 204, 2795-2801.

Tsai, T. Y.-C., Choi, Y. S., Ma, W., Pomerening, J. R., Tang, C. and Ferrell, J. E., Jr. (2008). Robust, tunable biological oscillations from interlinked positive and negative feedback loops. Science 321, 126-129.

Verberk, W. C. E. P., Bartolini, F., Marshall, D. J., Portner, H., Terblanche, J. S., White, C. and Giomi, F. (2016). Can respiratory physiology predict thermal niches? Ann. N.Y. Acad. Sci. 1365, 73-88.

Wasserthal, L. T. (1996). Interaction of circulation and tracheal ventilation in holometabolous insects. Adv. Insect Physiol. 26, 297-351.

Wasserthal, L. T. (2001). Flight-motor-driven respiratory air flow in the hawkmoth Manduca sexta. J. Exp. Biol. 204, 2209-2220.

White, C. R., Blackburn, T. M., Terblanche, J. S., Marais, E., Gibernau, M. and Chown, S. L. (2007). Evolutionary responses of discontinuous gas exchange in insects. Proc. Natl. Acad. Sci. USA 104, 8357-8361.

Wigglesworth, V. B. (1935). The regulation of respiration in the flea, Xenopsylla cheopis, Roths. (Pulicidea). Proc. R. Soc. Lond. B. 118

Woods, H. A. and Lane, S. J. (2016). Metabolic recovery from drowning by insect pupae. J. Exp. Biol. 219, 3126-3136.

Woods, H. A. and Smith, J. N. (2010). Universal model for water costs of gas exchange by animals and plants. Proc. Natl. Acad. Sci. USA 107, 8469-8474. 